Week 168, respectively, were: 7.5 and 8.6 (PF); 6.9 and 6.9 (RP); 10.4 and 11.6 (BP); 5.7 and $5.4(\mathrm{GH}) ; 7.2$ and 6.1 (Vitality [VT]); 5.0 and 4.5 (Social Function [SF]); 6.3 and 5.5 (Role-Emotional [RE]); and 6.1 and 4.8 (Mental Health [MH]).

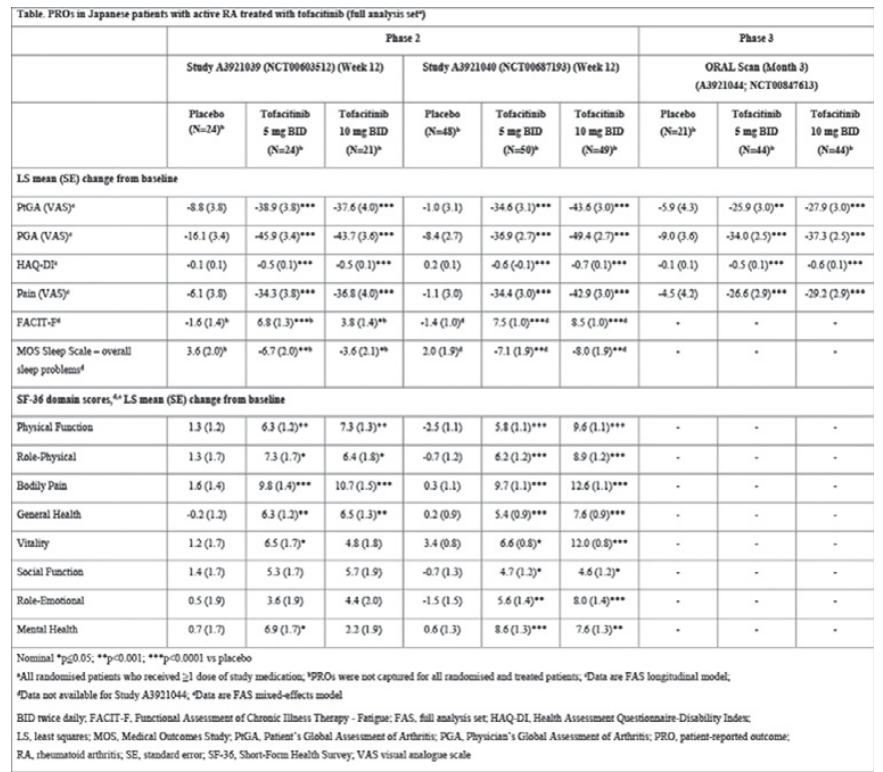

Conclusions: Tofacitinib 5 and $10 \mathrm{mg}$ BID significantly improved PROs in Japanese pts with RA enrolled in the P2, P3 and LTE studies.

Acknowledgements: This study was sponsored by Pfizer Inc. Editorial support was provided by K Haines of CMC and was funded by Pfizer Inc.

Disclosure of Interest: H. Yamanaka Grant/research support from: AbbVie, Astellas, Ayumi, Bayer, Bristol-Myers Squibb, Chugai, Daiichi-Sankyo, Eisai, Mitsubishi-Tanabe, MSD, Nippon Kayaku, Nippon Shinyaku, Ono, Pfizer Inc, Taisyo-Toyama, Takeda, Teijin Pharma, Torii, UCB, YL Biologics, Consultant for: AbbVie, Astellas, Ayumi, Bayer, Bristol-Myers Squibb, Chugai, Daiichi-Sankyo, Eisai, Mitsubishi-Tanabe, MSD, Nippon Kayaku, Nippon Shinyaku, Ono, Pfizer Inc, Taisyo-Toyama, Takeda, Teijin Pharma, Torii, UCB, YL Biologics, Speakers bureau: AbbVie, Astellas, Ayumi, Bayer, Bristol-Myers Squibb, Chugai, DaiichiSankyo, Eisai, Mitsubishi-Tanabe, MSD, Nippon Kayaku, Nippon Shinyaku, Ono, Pfizer Inc, Taisyo-Toyama, Takeda, Teijin Pharma, Torii, UCB, YL Biologics, Y. Tanaka Grant/research support from: AbbVie, Astellas, Bristol-Myers Squibb, Chugai, Daiichi-Sankyo, Eisai, Mitsubishi-Tanabe, MSD, Takeda, Consultant for: AbbVie, Asahi Kasei, Astellas, Bristol-Myers Squibb, Chugai, Daiichi-Sankyo, Eli Lilly, GSK, Janssen, Mitsubishi-Tanabe, Pfizer Inc, Sanofi, Takeda, Teijin, YL Biologics, Speakers bureau: AbbVie, Asahi Kasei, Astellas, Bristol-Myers Squibb, Chugai, Daiichi-Sankyo, Eli Lilly, GSK, Janssen, Mitsubishi-Tanabe, Pfizer Inc, Sanofi, Takeda, Teijin, YL Biologics, T. Takeuchi Grant/research support from: AbbVie, Asahi Kasei, Astellas, Ayumi, Bristol-Myers Squibb, Chugai, DaiichiSankyo, Eisai, Taisyo-Toyama, Takeda and Teijin Pharma, Consultant for: AbbVie, Astellas, Bristol-Myers Squibb, Celtrion, Chugai, Daiichi-Sankyo, Eisai, Janssen, Mitsubishi-Tanabe, Nippon Kayaku, Pfizer Japan Inc, Takeda, Speakers bureau: AbbVie, Asahi Kasei, Astellas, AstraZeneca, Bristol-Myers Squibb, DaiichiSankyo, Eli Lilly Japan, Janssen, Merck Serono, Mitsubishi-Tanabe, Nippon Kayaku, Novartis, Pfizer Japan Inc, Takeda, N. Sugiyama Shareholder of: Pfizer Inc, Employee of: Pfizer Japan Inc, T. Hirose Shareholder of: Pfizer Inc, Employee of: Pfizer Japan Inc, N. Yoshii Shareholder of: Pfizer Inc, Employee of: Pfizer Japan Inc, Y. Morishima Shareholder of: Pfizer Inc, Employee of: Pfizer Japan Inc, S. Toyoizumi Employee of: Pfizer Japan Inc

DOI: 10.1136/annrheumdis-2017-eular.1402

\section{THU0192 INFORMING PATIENTS ABOUT METHOTREXATE FOR THE TREATMENT OF RHEUMATOID ARTHRITIS WITH PATIENTS IN THE UNITED KINGDOM - A SURVEY OF RHEUMATOLOGISTS' STRATEGIES}

H.F. Hope ${ }^{1}$, S.M. Verstappen ${ }^{2}$, L. Cordingley ${ }^{3}$, K. Hyrich ${ }^{2} .{ }^{1}$ NIHR Manchester Musculoskeletal Biomedical Research Unit; ${ }^{2}$ Arthritis Research UK Centre for Epidemiology; ${ }^{3}$ Division for Musculoskeletal Research and Dermatological Science, University of Manchester, Manchester, United Kingdom

Background: Rheumatologists are the primary prescribers of methotrexate (MTX) for the treatment of rheumatoid arthritis (RA) in the United Kingdom (UK), however rheumatologists' views on their clinical practices are largely unknown. The authors conducted a qualitative study that highlighted a number of factors that contributed to their ability to discuss and commence MTX, which included how emotionally and cognitively prepared patients were to discuss treatments. The aim of this study was to further explore these themes with an online survey. Objectives: The aims of this study were:1)To establish the views of rheumatol- ogists about MTX for the treatment of rheumatoid arthritis (RA), 2)To examine if rheumatologists' views influenced discussing or commencing MTX during the initial consultation.

Methods: An online survey was designed and subsequently refined based on interviews with rheumatologists in the UK. The survey asked rheumatologists about their clinical setting, and their views and practices with respect to treating RA with MTX. Rheumatologists were asked how often specific pieces of MTX information were discussed during a consultation to commence MTX ( $5=$ Always to $1=$ never). They were also asked to identify the barriers to discussing these issues. The questionnaire included a factorial survey ie. two patient vignettes where we manipulated the following factors; male/female, emotionally prepared/unprepared and no/negative prior knowledge. Rheumatologists could select "information overload" as a barrier to communication with the patient. Random mixed effects models tested if these patient factors and information overload associated with 1) commencing and 2) discussing MTX.

Results: Ninety-six rheumatologists seeing approximately eight (IQR:5-12) new patients a week with $15 \pm 7$ years of experience completed the survey. Rheumatologists reported they often/always discussed ten (IQR 8-11) pieces of information during a consultation (Fig $1 \mathrm{~A}$ ), and information overload was identified as a communication barrier (48\%); $52 \%$ of rheumatologists expected the nurse to discuss MTX therapy (Fig 1B). Sixty rheumatologists completed one, and 56 rheumatologists two vignettes $(n=116)$. The vignette conditions and information overload significantly associated with "Commencing MTX" $\left(X^{2}=53.85, p<.0001\right.$, $\left.\mathrm{R}^{2}=.21\right)$ and discussing MTX $\left(X^{2}=30.9, \mathrm{p}=.002, \mathrm{R}^{2}=.19\right)$. Gender ${ }^{*}$ emotional preparedness $(\beta=-4.27,95 \% \mathrm{Cl}:-7.33,-1.21)$, and information overload ${ }^{*}$ emotional preparedness ( $\beta=-3.03,95 \% \mathrm{Cl}:-5.24,-.82)$ associated with MTX commencement, whilst only gender*emotional preparedness with discussing MTX ( $\beta=-3.86,95 \%$ Cl:-6.82, -.90).

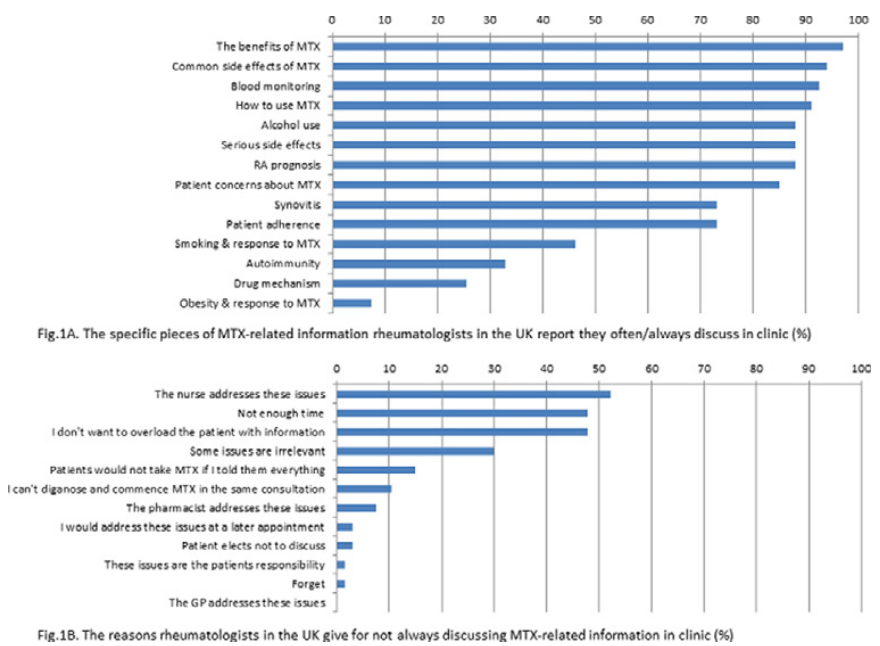

Conclusions: Currently UK rheumatologists convey a large amount of information to patients during early consultations. Almost half of rheumatologists identified the need to communicate large amounts of information in clinical consultations as a barrier to discussing MTX therapy. These data reflect the challenge clinicians face in trying to execute effective shared decision-making practices. Strategies to address patients' emotional responses to their diagnosis and being overloaded with MTX information are needed. Staggering presentation of information during clinical consultations may benefit some patients.

Disclosure of Interest: None declared

DOI: 10.1136/annrheumdis-2017-eular.2429

\section{THU0193 REESTABLISHMENT OF EFFICACY OF TOFACITINIB, AN ORAL JANUS KINASE INHIBITOR, IN RHEUMATOID ARTHRITIS PATIENTS AFTER TEMPORARY DISCONTINUATION}

J. Kaine ${ }^{1}$, J. Tesser ${ }^{2}$, R. DeMasi ${ }^{3}$, L. Takiya ${ }^{3}$, L. Wang ${ }^{4}$, M. Snyder ${ }^{3}$, H. Fan ${ }^{4}$, J. Wollenhaupt ${ }^{5} .{ }^{1}$ Sarasota Arthritis Research Center, Sarasota, FL; ${ }^{2}$ Arizona Arthritis \& Rheumatology Associates, Glendale, AZ; ${ }^{3}$ Pfizer Inc, Collegeville, PA; ${ }^{4}$ Pfizer Inc, Groton, CT, United States; ${ }^{5}$ Schön-Klinik Hamburg-Eilbek Teaching Hospital of the University of Hamburg, Hamburg, Germany

Background: Tofacitinib is an oral Janus kinase inhibitor for the treatment of rheumatoid arthritis (RA).

Objectives: To assess the efficacy and safety of tofacitinib after temporary discontinuation and reinitiation of therapy in RA patients (pts).

Methods: Data were collected from a randomised, parallel-group (grp), controlled, open label, vaccine sub-study in RA pts participating in a long-term extension (LTE) study (NCT00413699). Pts were $\geq 18$ years of age with active RA and had received tofacitinib $10 \mathrm{mg}$ BID for $>3$ months. The sub-study included 2 treatment (tx) grps: "continuous tx" (tofacitinib $10 \mathrm{mg}$ twice daily [BID] as monotherapy or with methotrexate [MTX]) and "interrupted tx" (tofacitinib withdrawn for 2 